\title{
A Statistical Comparison Of Accelerated Concrete Testing Methods
}

DENNY MEYER

D.H.Meyer@massey.ac.nz

Department of Statistics, Massey University, Albany

Private Bag 102-904, North Shore MSC, Auckland, New Zealand.

\begin{abstract}
Accelerated curing results, obtained after only 24 hours, are used to predict the 28 day strength of concrete. Various accelerated curing methods are available. Two of these methods are compared in relation to the accuracy of their predictions and the stability of the relationship between their 24 hour and 28 day concrete strength. The results suggest that Warm Water accelerated curing is preferable to Hot Water accelerated curing of concrete. In addition, some other methods for improving the accuracy of predictions of 28 day strengths are suggested. In particular the frequency at which it is necessary to recalibrate the prediction equation is considered.
\end{abstract}

Keywords: Dynamic Linear Model, CUSUM Test, Recalibratio.

\section{Introduction}

Concrete testing is performed in order to determine whether specified strength requirements are met. Ordinary strength tests involve the manufacture of test specimens which are cylindrical in shape measuring $200 \mathrm{~mm}$ long with a diameter of $100 \mathrm{~mm}$. These specimens are formed by pouring newly mixed concrete into appropriate moulds. The specimens are kept at room temperature for 28 days during which time the concrete hardens and strengthens. The specimens are then crushed and the stress at breakage is referred to as the 28-day strength of the concrete.

Results of the 28-day tests determine if adjustments are needed in the concrete recipe in order to satisfy the concrete strength specifications. With present methods of rapid construction it is imperative that methods be developed to estimate the 28-day strength of concrete cylinders at an earlier age. The ACI(1987) Manual of Concrete Practice suggests two procedures which can be used to provide an indication of the 28-day strength of concrete after only 24 hours. These procedures produce accelerated strengths which are obtained in exactly the same way as the 28-day strengths, except that the specimens are heated and then crushed after only 24 hours. These two procedures are defined as follows:

i)Warm Water Method, 23 to 24 hours at $35^{\circ} \mathrm{C} \pm 3^{\circ} \mathrm{C}$.

ii)Boiling Water Method, 23 hours at $21^{\circ} \mathrm{C} \pm 5^{\circ} \mathrm{C}$ and 3.5 hours at $100^{\circ} \mathrm{C}$. 
If data consisting of accelerated 24-hour strengths and the corresponding 28-day strengths for the same concrete batches are collected, then the relationship between these two strengths can be modelled, allowing the prediction of 28-day strengths from accelerated 24-hour strengths. Ideally a straight line can be used to model this relationship. It would obviously be useful to know which of the above accelerated curing methods produces the more accurate predictions of 28-day strengths. In addition it would be useful to know how often the relevant equations should be recalibrated. This study attempts to answer these two questions.

\section{The Data}

In this study an attempt is made to compare two accelerated curing methods using two historical data sets. The first data set consists of Warm Water accelerated 24-hour strengths and the corresponding 28-day strengths, collected during the period 1993-1995 in Auckland. The second data set consists of Hot Water accelerated 24-hour strengths and the corresponding 28-day strengths, collected during the period 1986-1990 in Wellington. The Hot Water accelerated curing method is a modification of the Boiling Water Method described above, involving temperatures of $70^{\circ} \mathrm{C}$ for approximately 20 hours.

Both data sets consist of compressive strength measurements for concrete specimens produced approximately on a daily basis. The two data sets were collected by production staff of Firth Concrete in order to test the usefulness of the Hot and Warm Water accelerated curing methods. Although the source of the cement was the same for both tests (Portland Cement), the cement itself was obviously different because the time periods were different. In addition the other ingredients of the concrete, namely aggregate, sand and water, differed as a result of the different locations. Basalt is the aggregate used in Auckland while Greywacke is used in Wellington.

There are three environmental variables, namely aggregate, ambient weather conditions and, in particular, cement chemistry, which are known to influence the relationship between accelerated 24-hour and 28-day strengths at any site. Other environmental variables such as variation in water and sand composition are thought to have little, if any, influence on this relationship.

As explained later, the aggregate effect is only of importance for very strong ( $>45 \mathrm{Mpa}$ ) concretes. Ambient weather conditions affect the curing process thus influencing the relationship between 28-day strengths and accelerated 24-hour strengths. Cement chemistry tends to vary systematically over time as a result of chemical variation in the (mined) raw materials used to produce the cement. This change in chemistry alters the chemical reaction which takes place when the concrete is mixed, thus changing the relationship between accelerated 24-hour strengths and 28-day strengths. Figure 1 shows how a weighted average of chemical analyses varied during the space of one year. The weights chosen for each chemical account for the highest possible percentage of variation and were obtained from the first principal component. This figure shows a gradual but persistent trend which had a 
pronounced effect on the relationship between accelerated 24-hour and 28 day strengths during this period.

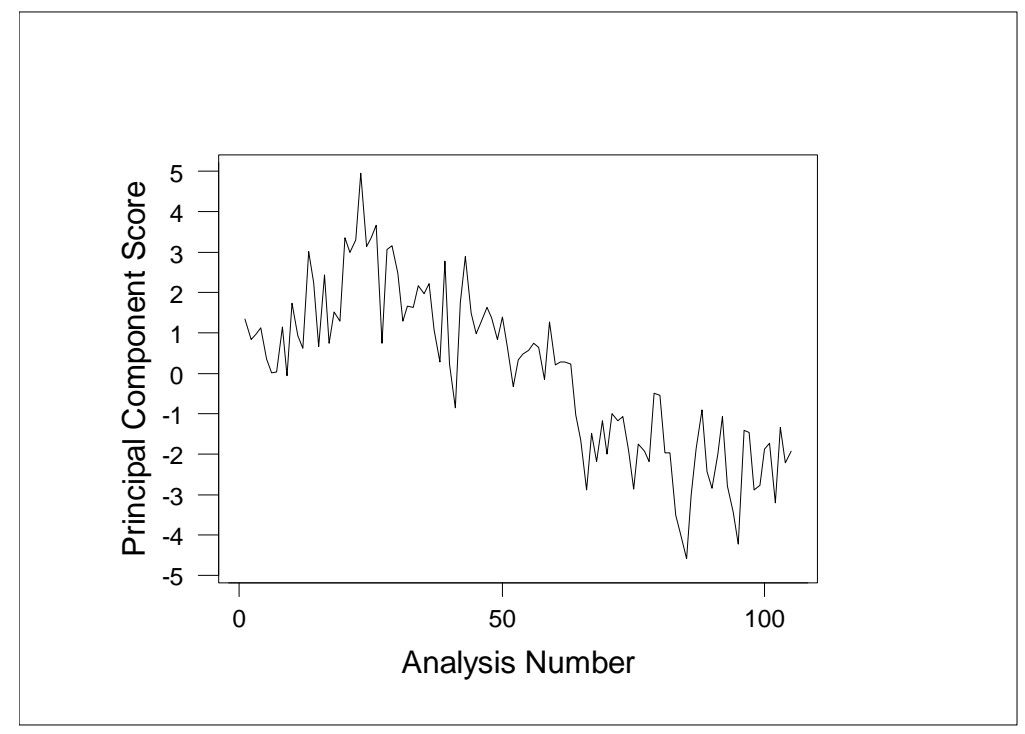

Figure 1.: Variation in cement chemistry over one year

The data are plotted in Figures 2 and 3, with 28-day strengths on the vertical (Y) axis and the corresponding accelerated 24-hour strengths on the horizontal (X) axis. Predicted values have been obtained from the equation

$$
\mathrm{Y}_{\mathrm{t}} \quad=\alpha+\beta \mathrm{X}_{\mathrm{t}}-\gamma \mathrm{X}_{\mathrm{t}}^{2} \text {. }
$$

The curvature apparent in these graphs can be attributed to a change in failure mode occurring in high strength concretes. For 28-day strengths in excess of approximately 45 $\mathrm{Mpa}$, concrete tends to experience aggregate failure rather than matrix (bonding) failure. Aggregate failure reduces the 28-day strength of this concrete but not its accelerated one-day strength. By excluding all concrete with compressive strengths in excess of $45 \mathrm{Mpa}$ we shall therefore eliminate the affect of aggregate on compressive strength in our two data sets. In view of the differing aggregates used in Auckland and Wellington this will permit a more reliable comparison of the Warm and Hot Water curing methods. At the same time the curvature is eliminated, producing a simple straight line relationship between accelerated 24hour and 28-day strengths.

\section{Methodology}


A first comparison of the two curing methods involves a comparison of the simple linear regression models fitted to their respective data. The relative magnitudes of the residual standard deviations give a rough indication of the robustness of the two methods to environmental variability. However, this analysis effectively assumes an equal amount of variation in ambient weather conditions and cement chemistry for the two data sets. This is not justified.

A better approach is to fit dynamic linear models to the data which allow the regression parameters to vary over time. These models incorporate changes in ambient weather conditions and cement chemistry in their varying parameters. The residual standard deviations therefore allow for different rates of environmental variability in the two data sets, giving a more reliable comparison of the predictive accuracy of the two methods.

Both the standard regression and the dynamic linear model analyses produce smaller residual standard deviations for the Warm Water Method, suggesting that the Warm Water Method is more robust and hence, more reliable, than the Hot Water method. The rest of the paper considers practical ways of improving on this accuracy.

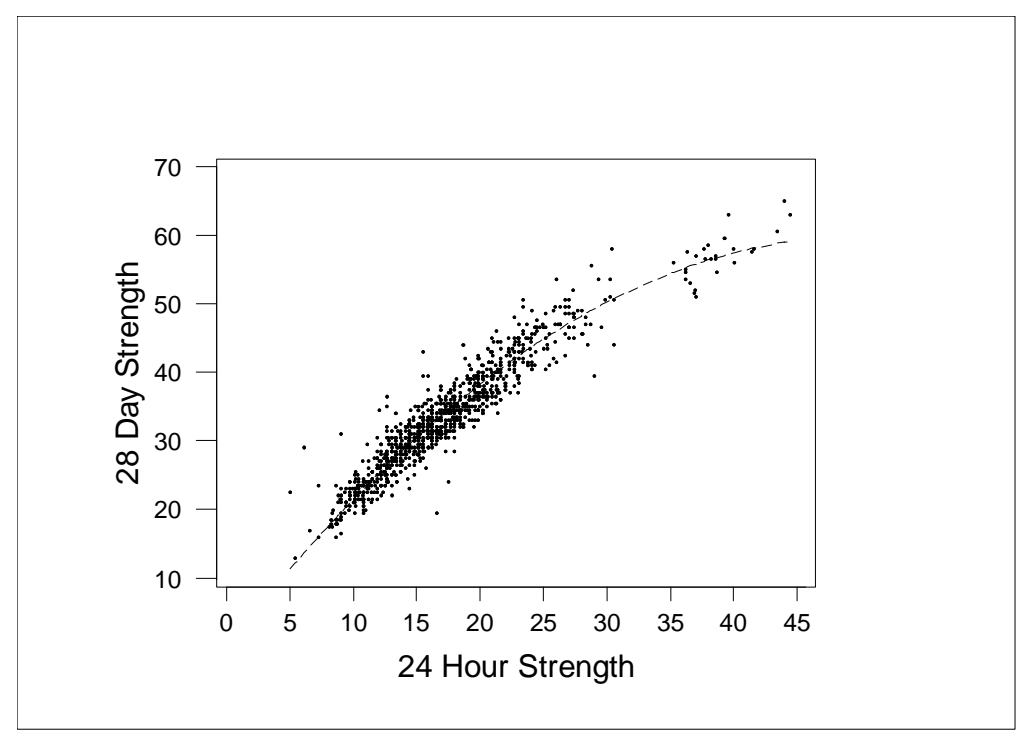

Figure 2 . Relationship between 28 day strengths and Hot Water accelerated 24 hour strengths - (Wellington data) 


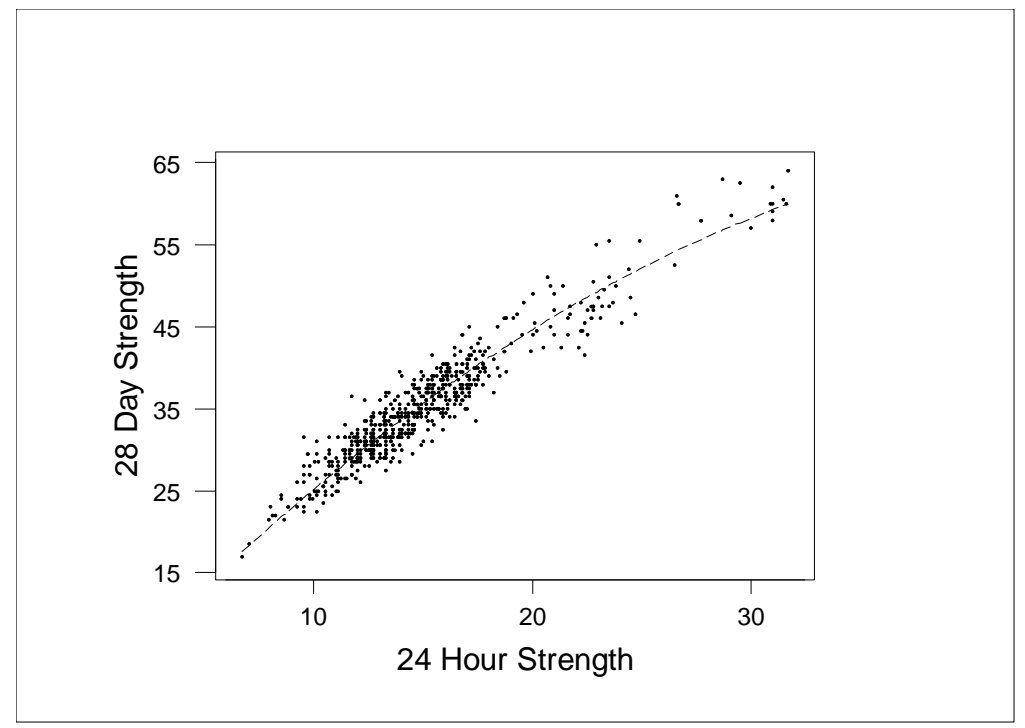

Figure 3. Relationship between 28 day strengths and Warm Water accelerated 24 hour strengths - (Auckland data)

At Firth Concrete 28-day strengths are predicted from 24-hour strengths using regression lines. In view of the changing relationship between 24-hour and 28-day strengths it is necessary for the production staff to regularly recalibrate these regression equations. This paper estimates how often this recalibration needs to be done. A CUSUM test proposed by Brown, Durbin and Evans (1975) is used to determine when a statistically significant change in the relationship between 24-hour and 28-day results has occurred. These results suggest how often it is necessary for the regression equations to be recalibrated.

Other improvements suggested in this paper involve the incorporation of cement chemistry into the regression equation itself and the inclusions of quadratic terms to allow for predictions for high strength concrete $(>45 \mathrm{Mpa})$.

\section{Analysis}

Three different analyses have been performed. In the first analysis 28-day strengths (Y) were regressed on 24-hour strengths $(\mathrm{X})$ ignoring all observations with 28-day strength in excess of $45 \mathrm{Mpa}$ so as to remove the influence of the aggregate used. The results are shown in Table 1. The smaller residual variance for the Warm Water method suggest that this method will produce more accurate predictions of 28 day strengths and that this method is more robust to environmental variability. However, this conclusion assumes that there was the same amount of environmental variability experienced during both tests. In view of the 
differences in time, duration and place this assumption is likely to be invalid. The significant correlations between consecutive errors is a symptom of the environmental variability and, as explained below, means that the residual standard deviations are under-estimated.

Table 1. Standard Regression Analysis

\begin{tabular}{lll}
\hline & Hot Water Method & Warm Water Method \\
\hline Intercept (standard error) & $8.767(0.343)$ & $9.086(0.507)$ \\
Slope (standard error) & $1.433(0.021)$ & $1.742(0.036)$ \\
Residual Standard Deviation(s) & 2.490 & 2.136 \\
R-Squared & $84.3 \%$ & $81.4 \%$ \\
Number of Concrete Batches(n) & 898 & 553 \\
Correlation consecutive errors & 0.25 & 0.31 \\
\hline
\end{tabular}

When 28-day strengths are regressed on one-day strengths, the changing chemical composition of the cement and ambient climate causes autocorrelated errors, invalidating the regression assumptions. As discussed by many authors (e.g. Neter, Wasserman and Kutner(1990)) autocorrelated errors mean that, although the regression coefficients are still unbiased, they no longer have the minimum variance property and may be quite inefficient. In addition the variance of the error terms and the standard error of the regression coefficients may be seriously under-estimated. This makes the residual standard deviation an unreliable performance criterion for comparing the two accelerated curing methods in this situation.

The best method for solving the problem of autocorrelated regression errors is to find and then introduce the key missing independent variables, ambient weather and cement chemistry in this case, into the regression. However, for these data this is not possible. It is impossible to determine the chemical composition of the cement that was used to manufacture any particular concrete specimen during the testing periods because this information was not collected at the time. A second approach for solving the problem of autocorrelated errors addresses the changing chemical composition of the cement indirectly, by permitting changes in the linear relationship between accelerated 24 hour and 28-day strengths. In this approach the coefficients for the linear relationship are not static but change over time.

This second analysis is based on a dynamic linear regression procedure proposed by West and Harrison (1989) and Pole, West and Harrison (1994). The model can be described as follows. Let $\mathrm{Y}_{\mathrm{t}}$ denote the 28-hour strength for batch $\mathrm{t}$ and let $\mathrm{X}_{\mathrm{t}}$ denote the (accelerated) 24hour strength for batch $t$. Then,

$$
\begin{aligned}
& Y_{t}=a_{t}+b_{t} X_{t}+z_{t} \\
& a_{t}=a_{t-1}+e_{t} \\
& b_{t}=b_{t-1}+v_{t}
\end{aligned}
$$


The errors $\mathrm{z}_{\mathrm{t}}, \mathrm{e}_{\mathrm{t}}$ and $\mathrm{v}_{\mathrm{t}}$ are assumed to be independent and normally distributed since normality is the usual assumption for concrete strengths (Harris (1984)). It may appear that the above model formulation cannot be useful because it contains more parameters $(2 n)$ than observations ( $n)$. However, this is an incorrect perception because the parameter sets $\left(a_{t}, b_{t}\right)$ are stochastically related in time with the stochastic elements $\left(\mathrm{z}_{t}, \mathrm{e}_{\mathrm{t}}\right.$ and $\left.\mathrm{v}_{\mathrm{t}}\right)$ allowing for some degree of information loss as time evolves. This ensures that the past data does not overwhelm the latest data when forecasting the future.

If this model is fitted to the Hot and Warm Water data using the BATS software (West and Harrison (1994)), the graphs shown in Figures 4 and 5 are obtained for the estimated slope coefficients and their $90 \%$ confidence intervals. As expected there was clearly significant variation in the slope coefficients $\left(b_{t}\right)$ over time.

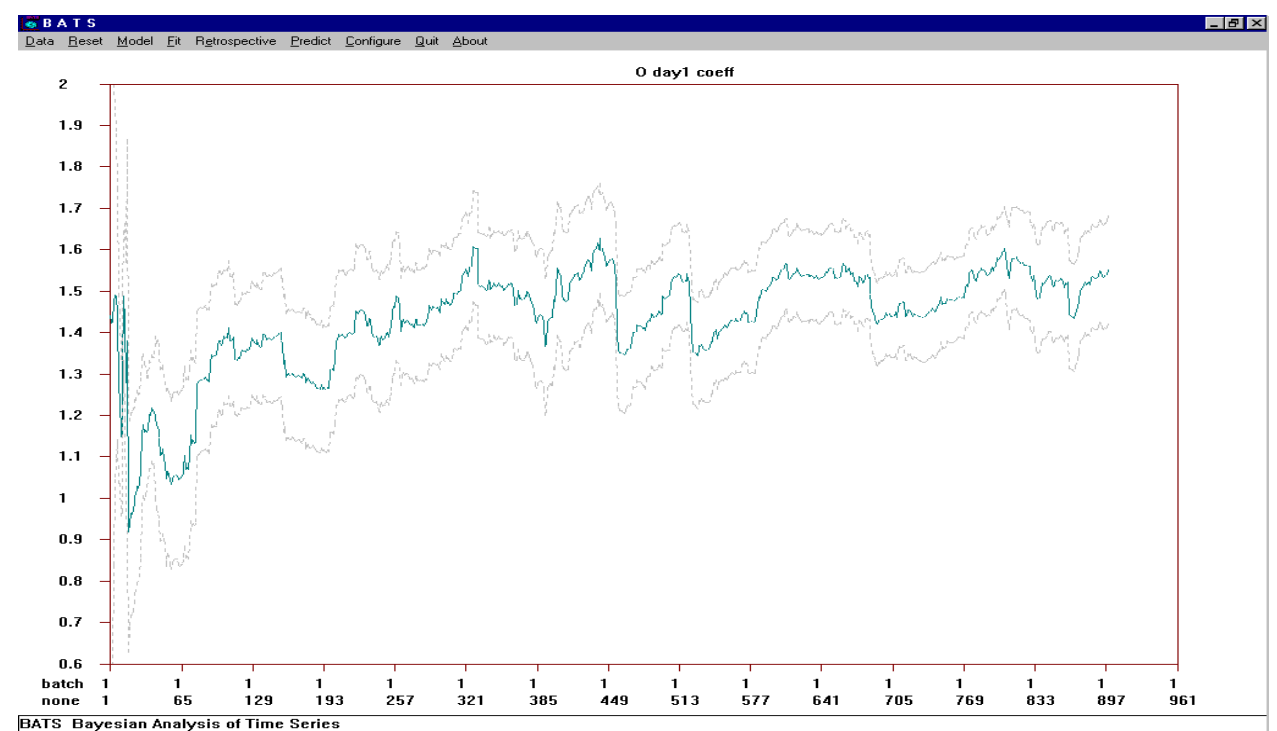

Figure 4 . Hot Water Accelerated Curing - Dynamic Linear Model Slope Coefficient $\left(b_{t}\right)$ 


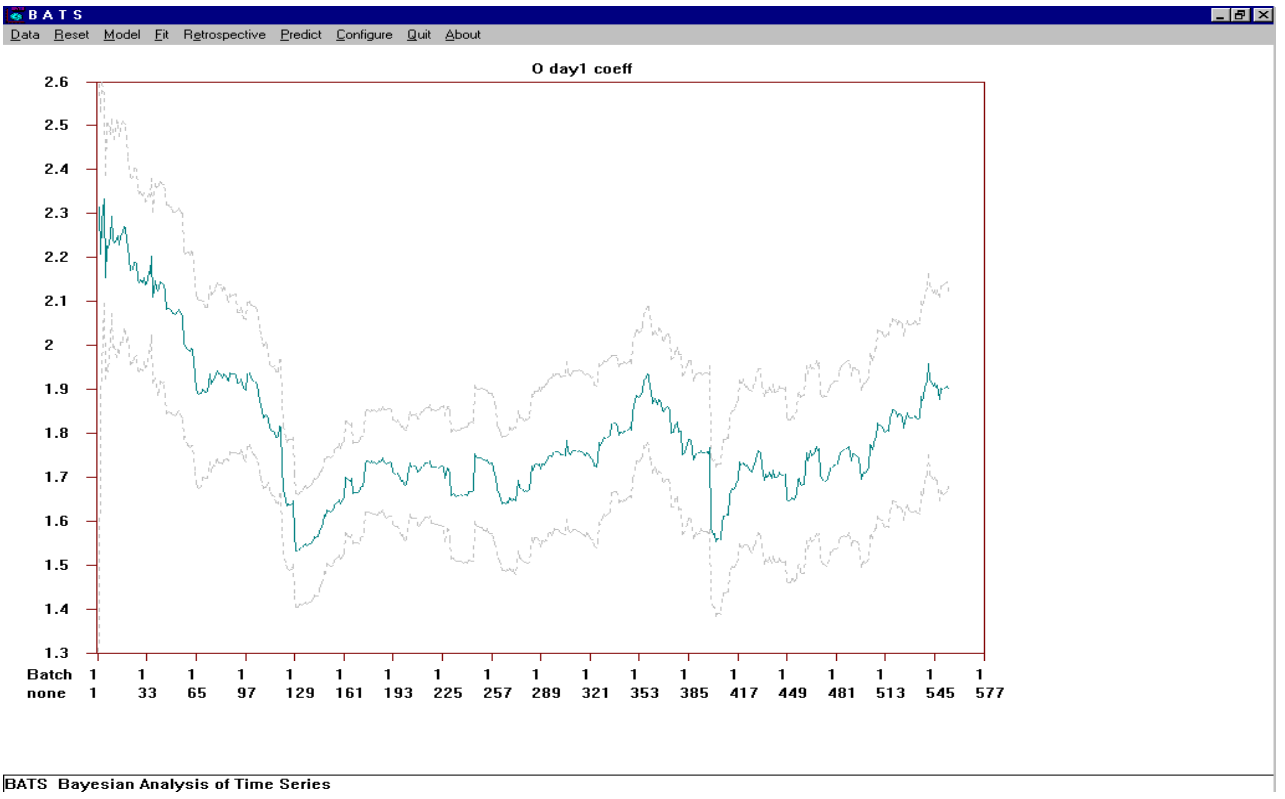

Figure 5. Warm Water Accelerated Curing-Dynamic Linear Model Slope Coefficient $\left(b_{t}\right)$

Although the mean slope for the dynamic models fitted in Table 2 are similar to those for the static linear models fitted in Table 1 , the $\mathrm{z}_{\mathrm{t}}$ residual standard deviation is smaller as a result of the better fit obtained from the dynamic models. The high standard deviations associated with the regression parameters, $a_{t}$ and $b_{t}$, are evidence of a changing relationship. The Warm Water estimates for these parameters have higher standard deviations than the Hot Water estimates. This suggests that there was more environmental variability during the Warm Water experiment. The smaller $\mathrm{z}_{\mathrm{t}}$ residual standard deviation for the Warm Water experiment suggests that this method is more robust to environmental variability than the Hot Water Method. The insignificant correlation between consecutive residuals indicates that these standard deviations are reliable.

Table 2. Dynamic Linear Model analysis

\begin{tabular}{lll}
\hline & Hot Water Method & Warm Water Method \\
\hline Mean Intercept & 8.78 & 8.25 \\
(standard deviation) & $(2.57)$ & $(2.69)$ \\
Mean slope & 1.43 & 1.80 \\
(standard deviation) & $(0.125)$ & $(1.59)$ \\
Residual Standard Deviation (s) & 2.42 & 2.01 \\
Correlation consecutive & NOT SIGNIFICANT & NOT SIGNIFICANT \\
residuals & & \\
\hline
\end{tabular}


The first two analyses have suggested that the Warm Water Method is more reliable than the Hot Water Method. The second analysis has shown that a dynamic linear model can adjust for changes in the relationship between 24-hour and 28-day strength which are caused by long-term factors, thus producing more reliable predictions. At this time the dynamic linear model is not used in concrete production at Firth Concrete. Instead simple regression models are recalibrated approximately every 6 months. Our third analysis attempts to assess the viability of this strategy. The difference in aggregate for the two tests is not relevant in this analysis because there is no comparison of the Hot and Warm Water Methods. In addition it is important to preserve continuity in time by minimising the amount of missing data. Consequently all the data shown in Figures 2 and 3 have been used in this analysis except for the super-strength Wellington concrete which has 24-hour strengths in excess of 35Mpa. As explained previously the super strength concrete destroys the straight line relationship for the Hot Water data.

Brown et al(1975) recommend a CUSUM test for determining when a significant change in a straight line relationship has occurred. Using the first k observations to initialise the process, recursive residuals $\left(\mathrm{w}_{\mathrm{r}}\right)$ are defined using the following formula for $\mathrm{r}=\mathrm{k}+1, \ldots \mathrm{n}$ :

$$
w_{r}=\frac{Y_{r}-X_{r}^{\prime} B_{r-1}}{\sqrt{\left(1+X_{r}^{\prime}\left(x_{r-1}^{\prime} x_{r-1}\right)^{-1} X_{r}\right)}}
$$

where $B_{r}$ represents both the regression parameter estimates based on the first $r$ observations,

and $\mathrm{x}_{\mathrm{r}-1}^{\prime}=\left[\mathrm{X}_{1}, \ldots, \mathrm{X}_{\mathrm{r}-1}\right]$. The test statistic is defined as

$$
W_{r}=\frac{\sum_{j=k+1}^{r} w_{j}}{\frac{1}{n-k} \sqrt{\sum_{j=k+1}^{n} w_{j}^{2}}}
$$

with control lines drawn through the points $(\mathrm{k}, \pm \mathrm{a} \sqrt{ }(\mathrm{n}-\mathrm{k}))$ and $(\mathrm{n}, \pm 3 \mathrm{a} \sqrt{ }(\mathrm{n}-\mathrm{k}))$ with "a" set equal to $1.143,0.948$ and 0.850 for a significance level of $1 \%, 5 \%$ and $10 \%$ respectively. When this test is applied to the Hot and Warm Water test results in Figures 6 and 7 with $\mathrm{k}=10$, it appears that a significant change in the relationship between accelerated 24-hour strengths and 28-day strengths is first detected after 38 and 31 batches respectively. Since the data were collected on a daily basis, approximately, this suggests that, on average, a recalibration of the regression equation is required every 6 weeks rather than every 6 months. 


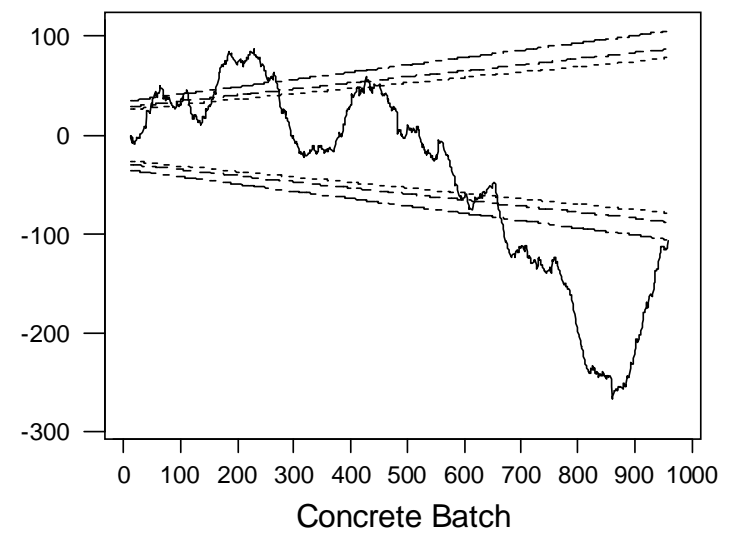

Figure 6. CUSUM Test for a Significant Change in the Relationship between 24-hour Accelerated Strength and 28-day Strength : 99\%, 95\% and 90\% limits shown Hot Water Curing

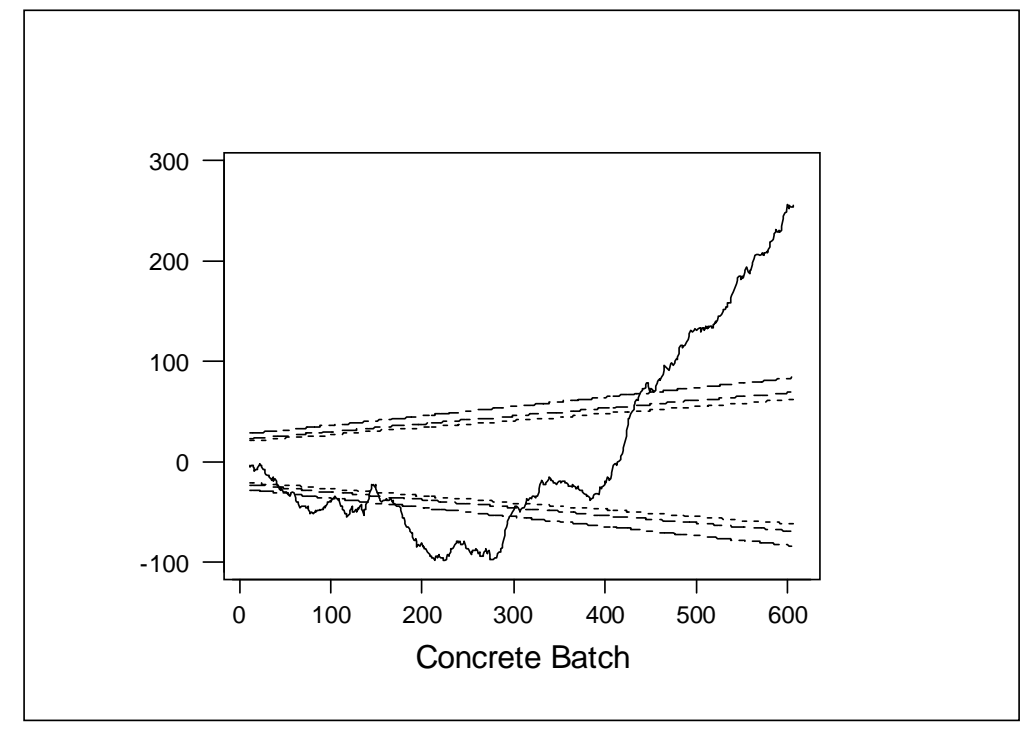

Figure 7. CUSUM Test for a Significant Change in the Relationship between 24-hour Accelerated Strength and 28-day Strength : 99\%, 95\% and 90\% limits shown Warm Water Curing 
Resetting the CUSUM equal to zero whenever a signal occurred, a set of run lengths were obtained for both data sets. The summary statistics shown in Table 3 indicate that the significance level chosen for the CUSUM test has a major influence on the recalibration decision, increasing the average run length by more than $40 \%$ when the significance level is reduced from $10 \%$ to $1 \%$. The medians and standard deviations are indicative of a right skewed distribution. This means that there will occasionally be long periods of time during which no calibration is required. However, the minimum values indicate that at other times continuous recalibration is required. Note that a k-value of 10 means that run lengths of less than 11 are impossible for this test.

Table 3. Run Lengths for CUSUM Test

\begin{tabular}{ccccccc}
\hline $\begin{array}{c}\text { Curing } \\
\text { Method }\end{array}$ & $\begin{array}{c}\text { Significanc } \\
\text { e Level }\end{array}$ & $\begin{array}{c}\text { Mean Run } \\
\text { Length }\end{array}$ & Median & $\begin{array}{c}\text { Standard } \\
\text { Deviation }\end{array}$ & Minimum & Maximum \\
\hline Hot & $1 \%$ & 59.4 & 56.5 & 44.6 & 12 & 132 \\
Hot & $5 \%$ & 47.5 & 34.5 & 39.3 & 11 & 124 \\
Hot & $10 \%$ & 41.3 & 20.0 & 36.5 & 11 & 122 \\
Warm & $1 \%$ & 49.2 & 34.5 & 45.4 & 11 & 138 \\
Warm & $5 \%$ & 37.4 & 25.0 & 34.2 & 11 & 118 \\
Warm & $10 \%$ & 33.3 & 24.0 & 31.3 & 11 & 124 \\
\hline
\end{tabular}

\section{Conclusion}

Two attempts have been made to compare the robustness of the Warm and Hot Water accelerated curing methods to environmental variability, cement chemistry variation in particular. This comparison is complicated by the fact that the Warm and Hot Water tests were run in different years and in different locations using different aggregates. This meant that the aggregate effect was confounded with the method of accelerated curing. By considering only concretes with a strength of less than $45 \mathrm{Mpa}$ the only known result of this confounding has been removed.

In the first attempt a straight line was fitted to the Warm and Hot Water data. It was found that the residual variance for the Warm Water Method was smaller that that for the Hot Water Method, suggesting that the Warm Water Method was more accurate or that there was more environmental variation for the Hot Water test than for the Warm Water test.

The second attempt involved a dynamic linear model which allowed the parameter estimates to change over time, in response to changes in cement chemistry (and ambient weather conditions). This method removed the effect of long-term variability by allowing the regression parameters to vary over time. The greater standard deviations associated with the Warm Water regression parameters suggested that there was actually less environmental variation for the Hot Water test than for the Warm Water test. The residual variance for this model was again smaller in the case of the Warm Water Method, confirming that this method may indeed be more reliable than the Hot Water Method. 
In practice the regression equations are recalibrated approximately every 6 months. In order to check this practice the data were subjected to a CUSUM test for a change in the relationship between the accelerated 24 hour and 28 day strengths. The mean run lengths suggested that the recalibration period should be reduced to every 6 weeks. However, the skewness of the run length distribution means that it is advisable to run the CUSUM test more regularly than this in case more frequent recalibration is necessary.

These results suggest that the simpler Warm Water Method of accelerated curing is preferable to the Hot Water Method and that the equation used to predict 28-day strengths needs to be regularly checked, and recalibrated if necessary. However, this study has also suggested three additional methods for improving the accuracy of 28-day concrete strength predictions.

Most importantly it is suggested that cement chemistry should be included as a predictor in the prediction equation. In addition it is suggested that a dynamic model which permits changes in the regression parameters over time is more appropriate than a static model. Finally, it is suggested that a single straight line model is not appropriate when the compressive strength of super-strength concrete is to be predicted. In view of the limited number of high strength batches it is probably not feasible to develop separate equations for these high strength concretes. Consequently a quadratic model is recommended to describe the relationship between accelerated 24 hour and 28 day strengths when high strength concretes are to be included in the analysis.

Further work is underway in regard to these recommendations.

\section{Acknowledgements}

The author wishes to thank Firth Industries of New Zealand for permitting her to work with them on this project. In addition she would like to thank the referees for their most valuable comments.

\section{References}

1. ACI. Use of Accelerated Strength Testing. ACI Manual of Concrete Practice, Part 5, American Concrete Institute, Detroit Michigan, 1987.

2. R.L. Brown, J. Durbin, and J.M. Evans. Techniques for Testing the Constancy of Regression Relationships over Time. Royal Statistical Society Journal, Series B, 37:149-192, 1975.

3. C.A.R.Harris. Statistics for Concrete - Part 1. Concrete Society Digest No. 6, The Concrete Society, London, 1984.

4. J. Neter, W. Wasserman and M.H. Kutner. Applied Linear Statistical Models, Irwin, 1990.

5. A. Pole, M. West and J. Harrison. Applied Bayesian Forecasting and Time Series Analysis. Chapman and Hall, USA,1994

6. M. West and J. Harrison. Bayesian Forecasting and Dynamic Models. Springer Verlag, 1989.. 


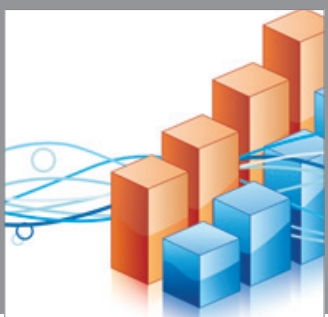

Advances in

Operations Research

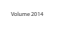

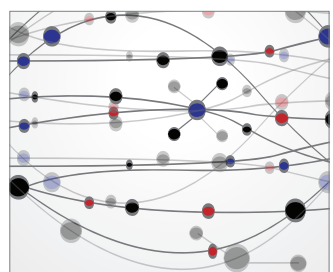

\section{The Scientific} World Journal
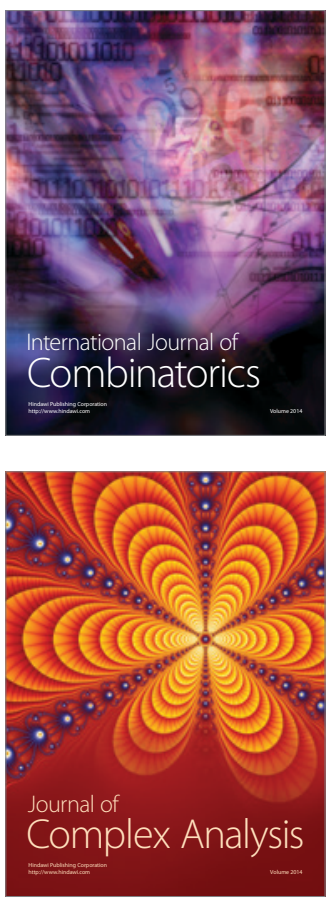

International Journal of

Mathematics and

Mathematical

Sciences
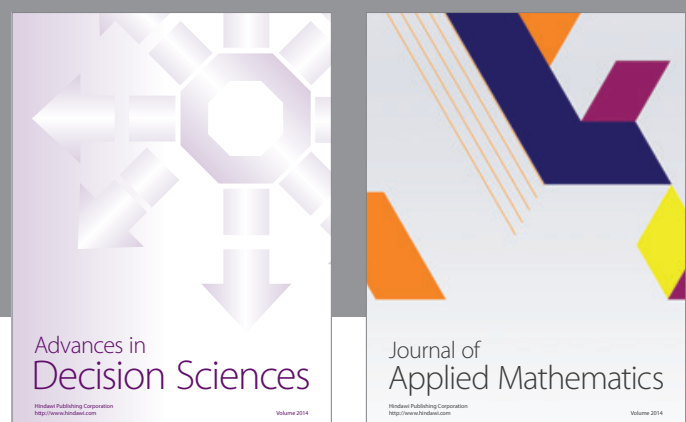

Journal of

Applied Mathematics
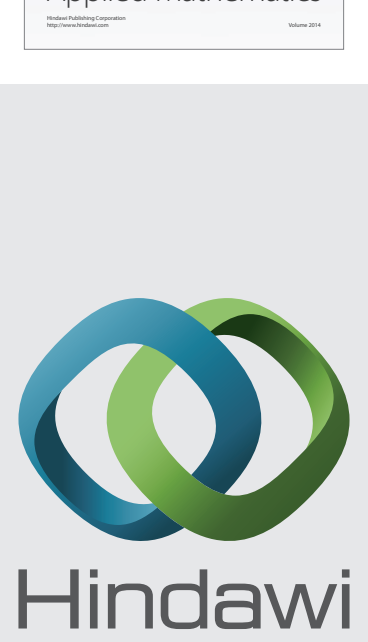

Submit your manuscripts at http://www.hindawi.com
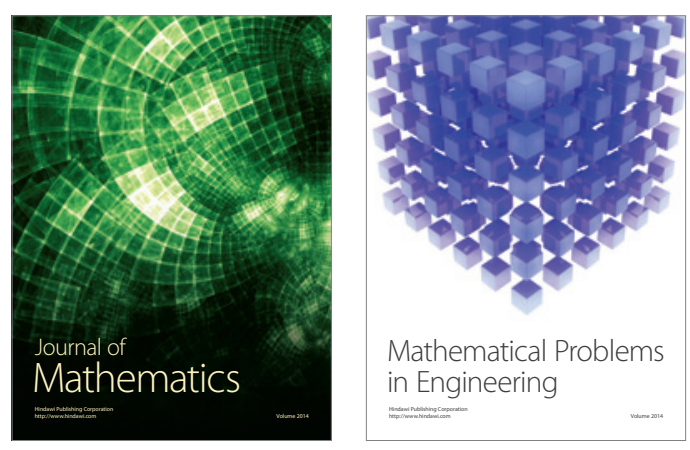

Mathematical Problems in Engineering
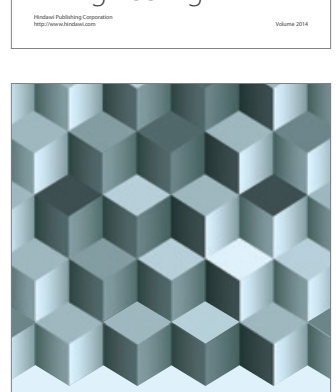

Journal of

Function Spaces
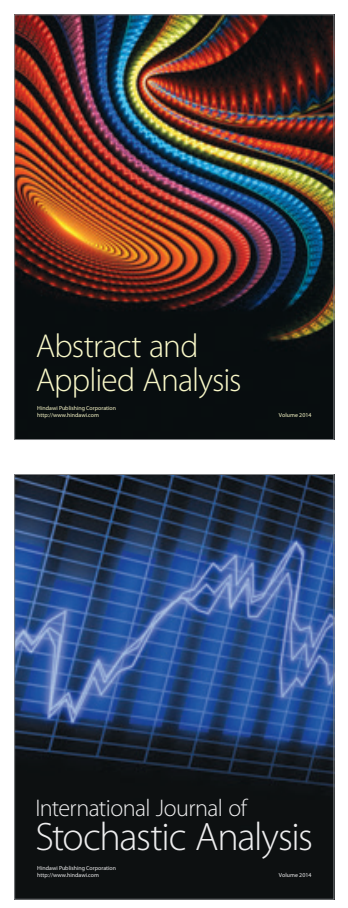

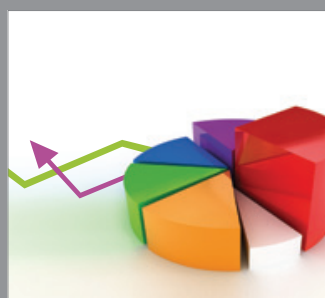

ournal of

Probability and Statistics

Promensencen
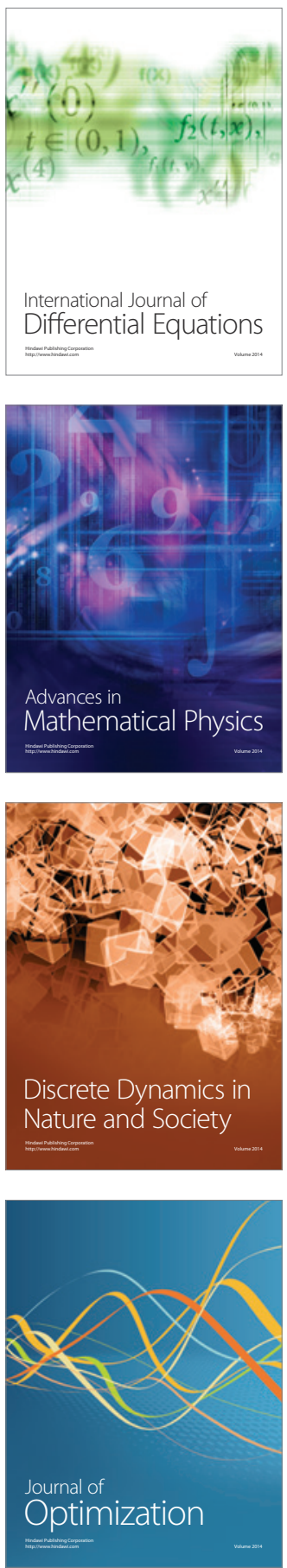